BOOK REVIEW

\title{
Michael D. Mehta (Ed.), Biotechnology Unglued: Science, Society \& Social Cohesion. Vancouver: UBC Press, 2005, 194 pp., \$29.95 paper.
}

\author{
Reviewed by Kimiko Inouye, Ryerson University
}

Biotechnology Unglued: Science, Society \& Social Cohesion engages with issues such as farming, food safety, genetic database collections, DNA testing, bioprospecting, and intellectual property. The intention of editor Michael Mehta is to examine these issues in relation to how they impact the social cohesion of society, in particular of communities more directly impacted. For example, Mehta writes about how genetically engineered seed technologies have impacted farming communities in Canada, while Jacqueline Broerse and Joske Bunders examine how these same technologies affect smaller-scale, resource-poor farmers in the South, and Kyle Eischen discusses the implications for the Icelandic population as a result of the creation of a national Iceland Genetic Database, which is largely controlled by the DeCode Genetics company.

While the concept of social cohesion provides an interesting basis upon which to evaluate the impact of new biotechnological developments, it is also somewhat misleading. Mehta's approach suggests that without biotechnology, society would be more unified, and in turn prepared to deal with various social, political, cultural and economic changes. Mehta does clarify that "cohesive communities are not necessarily more concerned about issues related to things such as equality of opportunity. In fact, some forms of social cohesion may help to reinforce practices that are inherently unjust" (2). Yet, even with such a clarification, Mehta's overall approach raises two concerns. First, do all communities and/or societies examined in Biotechnology Unglued thus qualify as cohesive to begin with? At what point does a community not qualify as socially cohesive? These questions are particularly important in considering Neil Gerlach's essay on the use of DNA testing in the investigation of criminal acts.

Gerlach's essay argues that DNA technologies "have already had significant impacts 
on criminal justice in particular and on social control in general" (117). Gerlach points out that in Canada a National DNA Data Bank exists, which is maintained by the Royal Canadian Mounted Police. Under Bill C-3, the DNA Identification Act, people convicted of designated offences are required "to provide samples of bodily substances for DNA analysis and storage" (120). A key argument made by Gerlach is that there has been little public debate on the implications of the Act. He attributes this to several factors. Of particular interest are certain "social forces", including "a fear of crime, the emergence of a surveillance society, changing definitions of criminality, and processes of technical rationalization in crime management agencies" (121). Given the racialized and classed lines along which people are criminalized in Canada, to what extent can the society as a whole be considered cohesive to begin with?

Perhaps more visible following the events of September 11, 2001, is how Muslim, Middle Eastern, South Asian, North African and West Indian communities in Canada, and abroad, are being targeted, suspected and arrested for alleged involvement in terrorist acts. Under the Criminal Code, conspiracy to carry out terrorist acts is considered a primary offence, which justifies the collection of DNA samples. Though Berlach does not elaborate on how the social forces he identifies relate to the criminalization of racialized and classed communities, this is an issue that requires critical examination, particularly when the overall approach in which his essay is situated assumes that the society in question can be considered socially cohesive.

The second concern is that Mehta's approach is not grounded in a more political economic analysis, which could help explain the underlying motivations of technological developments in capitalist, or predominantly capitalist societies. A key tendency of capitalist systems is the constant development of new technologies in order to further the exploitation of workers, and in turn, continuously generate greater returns on investment. Without such an analysis, which takes consideration of the more fundamental reasons behind biotechnology, Mehta's approach suggests that devoid of biotechnology, the communities of focus would be more cohesive. An inclusion of a Marxist conceptualization of technology would be helpful in providing for a more comprehensive analysis.

This is not to suggest that the particular implications that arise from biotechnology in various sectors are insignificant. From a sociological perspective, an investigation of these implications is extremely relevant. Biotechnology Unglued is undoubtedly successful in offering analyses on aspects of biotechnology that are necessarily critical, yet not often the focus of debate. More often public debates around biotechnology focus on food safety, while issues such as the increasing privatization of research, or the cultural appropriation of genetic resources are less visible. 
Annette Burfoot and Jennifer Poudrier's approach in comparing the extraction of genetic resources (as an extension of the colonial project) to "Modern Museums of Civilization" (133) is especially enlightening, as it reveals underlying power relations that inform acts of appropriation. Meanwhile, Robert Dalpé, Louise Bouchard and Daniel Ducharme's essay on the social dynamics of medical biotechnology research at particular institutions in North America and Europe uncovers the complexity of how public research institutions are implicated within objectives of the private sector, particularly in terms of intellectual property. This is an issue of particular relevance in Canada where public-private partnerships are increasingly supporting the infrastructural needs of medical biotechnology research, while direct research partnerships between private companies and public institutions are not uncommon. Overall, Biotechnology Unglued presents a forum in which an inclusive range of perspectives is thoughtfully offered. 